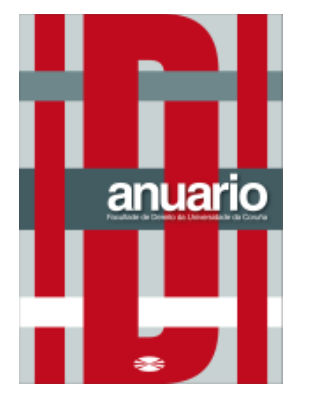

Anuario da Facultade de Dereito da Universidade da Coruña

Vol. 23 (2019), pp. 429-452

ISSNe: 2530-6324 || ISSN: 1138-039X

DOI: https://doi.org/10.17979/afdudc.2019.23.0.6031

\title{
LA REALIDAD JURÍDICA Y POLÍTICA EN LOS SISTEMAS DEMOCRÁTICO REPRESENTATIVOS
}

\section{THE LEGAL AND POLITICAL REALITY IN REPRESENTATIVE DEMOCRATIC SYSTEMS}

\author{
ENRIQUE SÉPTIMO RODRÍGUEZ* \\ Profesor de la Facultad de Derecho \\ Universidad Autónoma del Estado de México
}

\begin{abstract}
Resumen: El presente artículo pretende realizar una reflexión sobre la realidad jurídica y política que se vive en los Estados con sistema democrático representativo, motivo por el cual, se efectúa un estudio teórico de conceptos fundamentales, desde el origen y evolución de la democracia, hasta abordar conceptos inherentes a ella, como libertad, pueblo, soberanía y representación. Lo anterior, con el fin último de poder circunscribir la problemática que se genera en torno a las diferencias existentes entre lo jurídico y lo político. Todo lo anterior fundado en la premisa de que la única forma de alcanzar la libertad e igualdad es a través de la Democracia Constitucional.
\end{abstract}

Palabras clave: democracia, libertad, pueblo, parlamento, soberanía, mandato representativo y mandato imperativo.

\begin{abstract}
This article aims to reflect on the legal and political reality that is experienced in states with a representative democratic system, which is why a theoretical study of fundamental concepts is carried out, from the origin and evolution of the Democracy, to address concepts inherent in it, such as freedom, people, sovereignty and representation. The foregoing, with the ultimate goal of being able to circumscribe the problems that are generated around the differences between the legal and the political. All of the above was founded on the premise that the only way to achieve freedom and equality is through constitutional democracy.

\footnotetext{
* Maestro en Derecho con área terminal en Justicia Constitucional, por la Universidad Autónoma del Estado de México. Estudiante del Doctorado en Estudios Jurídicos y del Doctorado en Derecho Parlamentario en la Universidad Autónoma del Estado de México; Profesor de diversas asignaturas en la Facultad de Derecho de esta misma Universidad. Toluca, México. enriquesere@hotmail.com.
} 
Keywords: democracy, freedom, people, Parliament, sovereignty, representative mandate and imperative mandate.

Sumario: I. INTRODUCCIÓN. II. CONCEPTUALIZACIÓN, ORIGEN Y EVOLUCIÓN DE LA DEMOCRACIA. III. LA IDEA DE REPRESENTACIÓN POLÍTICA. IV. EL PARLAMENTARISMO: MANDATO IMPERATIVO Y REPRESENTATIVO. V. REALIDAD JURÍDICA Y POLÍTICA EN LA REPRESENTACIÓN. VI. CONCLUSIONES. VII. BIBLIOGRAFÍA.

\section{INTRODUCCIÓN}

El presente texto pretende realizar una reflexión, sobre la realidad jurídica y política que se presenta en los Estados con sistema democrático representativo, mediante el uso del método inductivo-deductivo. Por ello se inicia con la conceptualización de la democracia para hacer notar los diversos elementos que en ella convergen; indiscutiblemente el estudio de la democracia también implica hacerlo sobre las ideales de igualdad y libertad, ya que no se pueden concebir de manera aislada. En este sentido, se invoca el pensamiento de Pedro de Vega, estudioso de la Teoría del Estado y del Derecho Constitucional, quien sostenía que a través de éste último, se pueden hacer efectivas las viejas ideas de "Democracia", "Libertad" e "Igualdad", aunado al estudio de las teorías de los clásicos y renacentistas, como Aristóteles, Maquiavelo, Rousseau, Montesquieu, Locke, entre otros más; teóricos que se preocupaban por el ejercicio del poder y forma de gobierno, motivo por el cual, no se puede prescindir de ellos para entender la realidad y problemática actual.

Con base en lo anterior, más un estudio teórico que se efectúa respecto a la relación intrínseca que existe entre soberanía, pueblo, parlamento y mandato representativo, se pretende evidenciar la problemática que se genera en relación al distanciamiento entre la realidad jurídica y política (misma que se puede conciliar a través las mutaciones constitucionales), siendo ésta última, la que hace un uso indebido del mandato imperativo, en atención a que en la praxis, el representante (diputado) atiende a intereses particulares, principalmente al de su partido político, olvidándose del mandato representativo que le ha conferido el pueblo como soberano, para materializar la voluntad general.

El distanciamiento que se presenta hoy en día entre la realidad jurídica y política es innegable, lo cual en muchos de los casos ha llevado a que los funcionarios públicos actúen en contra de la ley, es decir, de forma ilegal, orillados a esto por presiones políticas y/o económicas, toda vez que tienen presente que si no lo hacen de tal manera, su carrera política se puede ver frustrada por no atender a aquellos intereses o indicaciones de sus superiores, quienes generalmente se las fijan antes de ocupar el cargo público, en este sentido, dichas condiciones deben de ser acatadas, aunque la obligación existente de hacerlo no es coercible o exigible jurídicamente, toda vez que los compromisos políticos 
que se adquieren se hacen, por obvias razones, fuera del amparo de la ley. Uno de los diversos compromisos que un representante adquiere al ocupar un lugar en las Cámaras, es el de obedecer las instrucciones que su partido político le impone, es ahí donde radica uno de los principales problemas, ya que ante este supuesto, se está frente a un mandato imperativo y no representativo, porque se atiende a intereses particulares de algunos grupos de poder y no a la voluntad general; lo correcto sería que una vez que los representantes ocuparán el cargo éstos no rindan cuentas directas u obedezcan a su partido político, sino a la colectividad; por otra parte, ¿qué pasa si éstos no rinden cuentas u obedecen a su partido político?, los remueve, lo cual obviamente no se realiza a través de un mecanismo jurídico sino mediante herramientas políticas como son las dimisiones en blanco, tema que se abordará en la parte final. En este sentido, el presente trabajo también pretende exponer que es lo que pasa cuando la realidad política se sobrepone a la realidad jurídica en los sistemas democráticos representativos, y cómo de alguna manera logran coexistir dentro de un mismo Estado.

\section{CONCEPTUALIZACIÓN, ORIGEN Y EVOLUCIÓN DE LA DEMOCRACIA}

De acuerdo con Kelsen la democracia es una necesidad para el desarrollo social ${ }^{1}$, idea que no se puede contravenir en pleno siglo XXI, ya que actualmente es el sistema que mayormente se ha adoptado a nivel mundial por parte de los Estados, en este mismo sentido, Pedro de Vega señala que, "es el único régimen éticamente defendible, políticamente coherente y científicamente explicable" ${ }^{2}$, dicha manifestación toma sentido, al comprender que la democracia también entraña los derechos fundamentales de libertad e igualdad, los cuales se convierten en propios límites del actuar del Estado ${ }^{3}$. También se puede entender como una forma de gobierno o sociedad, en la que la voluntad colectiva u orden social se encuentra depositado en el pueblo; en otras palabras, el gobierno es del pueblo y para el pueblo, donde existe identidad entre dirigentes y dirigidos ${ }^{4}$. Como principio constitucional, es la forma de Estado y de Gobierno, que como se ha dicho, se ha adoptado por la gran mayoría de países occidentales, pues se considera como la forma en la que el poder funciona y se ejerce siempre a través de la voluntad del pueblo o de algún medio atribuido a él ${ }^{5}$.

No obstante lo anterior, la organización política estatal puede o no operar de manera democrática; respecto a ello, Pedro de Vega, señala que el punto de partida del constitucionalismo moderno es la democracia, lo que implica que su esencia, sentido y finalidad respondan a la idea liberal; pues no en vano los términos, constitucionalismo y liberalismo, guardan estrecha relación. Aseveraciones que se relaciona con un concepto más elaborado, al de Estado constitucional democrático, en el cual no basta que el pueblo

\footnotetext{
${ }^{1}$ KELSEN, H., Teoría Pura del Derecho (1960), trad., de W. Roces, Porrúa, México, 1987, p. 35.

2 VEGA, P. DE, Estudios político-constitucionales, Instituto de Investigaciones Jurídicas, UNAM, México, 2016, p. 8.

${ }^{3}$ KRIELE, M., Introducción a la Teoría del Estado fundamentos históricos de la legitimidad del Estado constitucional democrático, Depalma, Buenos Aires, 1980, p. 470.

${ }^{4}$ KELSEN, H., Esencia y valor de la democracia (1977), trad. de R. Luengo Tapia y Legaz Lacambra L., Editorial Comares, Granada, 2002, p. 36.

${ }^{5}$ BÖCKENFÖRDE, E.W., La democracia como principio constitucional, en Estudios sobre el Estado de Derecho y la Democracia, trad. de R. de Agapito Serrano, Trotta, Madrid, p. 47.
} 
participe en la designación de gobernantes, sino que además existan mecanismo de control y de limitación del poder, en este sentido, solo cabe hablar de una Constitución moderna, cuando es el propio pueblo quien la establece y sanciona ${ }^{6}$. Por lo anterior, la democracia además de entenderse como el ejercicio del poder por el pueblo, también se entiende como una garantía de la libertad ${ }^{7}$. Hasta el momento como se ha observado el concepto de democracia involucra elementos como pueblo, representación, poder y libertad, los cuales se analizarán más adelante en el cuerpo del presente escrito.

Ahora bien, los orígenes de la democracia se encuentran en las ciudades griegas hace veinticinco siglos, etimológicamente, como se ha dicho, significa el gobierno del pueblo. Se encuentra conformada por dos conceptos: demos, que en aquella época significaba la "comunidad ateniense" reunida en la asamblea eklesía, donde se excluía a las mujeres y a los esclavos del derecho de ser considerados como ciudadanos; y kratos, gobierno. Los ciudadanos atenienses se reunían para deliberar sobre los asuntos de carácter público y participar en la toma de decisiones políticas, estas reuniones tenían un quórum de entre dos mil y tres mil ciudadanos, lo que hacía posible el ejercicio de la democracia participativa $^{8}$.

Desde la Grecia clásica hasta nuestros días, la concepción de la democracia ha evolucionado, al igual que la sociedad misma. En sus orígenes, se ejercía de manera directa, en atención a que la voluntad estatal era creada directamente por los ciudadanos reunidos en asamblea, aunque hay que precisar que no todos los habitantes tenían la calidad de ciudadanos, sino únicamente aquellos que nacían en Atenas y contaban con patrimonio, lo cual indica que no todos participaban en la toma de decisiones. Este tipo de democracia se empleaba para emitir sentencias en juicio, elecciones de jefes, declaración de guerras, etcétera, porque las normas jurídicas existentes solían ser consuetudinarias. La democracia directa, como se puede apreciar, en sus orígenes fue de sencilla aplicación en comunidades pequeñas y con pocas diferencias culturales ${ }^{9}$, pero con el surgimiento de los Estados modernos, donde por sus propias características relativas principalmente al número de población y extensión territorial, fue imposible que se siguiera llevando a cabo la democracia de identidad $^{10}$, por lo que la democracia representativa se constituyó como la única opción posible; situación que en su momento reconoció Rousseau, al señalar que "un gobierno democrático conviene más a una pequeña ciudad que a una nación. No se podría reunir a todo el pueblo de un país como al de una ciudad"11, lo cual indica, que para los grandes Estados no les es materialmente posible ejercitar la democracia participativa, en atención a que sería muy difícil reunir a la población en un lugar determinado para poder tomar decisiones en conjunto, es así que Rousseau acepta que ante este supuesto se debe de

\footnotetext{
6 VEGA, P. DE, Constitución y Democracia, en Rubio Núñez, Rafael (ed.), Obras Escogidas De Pedro De Vega, Centro de Estudios Políticos y Constitucionales, Madrid, 2017, p. 212.

${ }^{7}$ Ibid., pp. 214-2015.

${ }^{8}$ SARTORI, G., Teoría de la democracia, vol. 2, Alianza Editorial, México, 1988, p. 42.

${ }^{9}$ KELSEN, H., Teoría General del Estado (1925), trad. de Legaz Lacambra L., Editorial Comares, Granada, 2002, p. 555.

${ }^{10}$ RUIPÉREZ, J., Libertad Civil e ideología democrática De la Conciliación entre democracia y libertad a la confrontación liberalismo-democracia, Instituto de investigaciones Jurídicas, UNAM, México, 2008. p. 36.

${ }^{11}$ ROUSSEAU, J.-J., Proyecto de Constitución para Córcega. Consideraciones sobre Gobierno de Polonia y su proyecto de reforma (1765), trad. de Hermosa Andujar A., Tecnos, Madrid, 1988, p. 10.
} 
emplear la democracia representativa, pero bajo diversas reglas que más adelante se expondrán.

Javier Ruipérez, retomando brillantemente el pensamiento clásico de Aristóteles, en el marco de la voluntad del pueblo, hace referencia a la existencia de dos tipos de democracia, aquella que se puede considerar legal y a contrario sensu, la ilegal. La primera, como se puede inferir es aquella que está acorde a la ley, es decir, es una forma pura de gobierno a la cual Aristóteles la denominó politeia. Por otra parte la democracia ilegal, la de los demagogos, se convierte en una forma impura de democracia, donde éstos, hacen valer la voluntad de la asamblea a la que manipulan ${ }^{12}$. Lo anterior, significa que en la democracia legal, los gobernantes se encuentran subordinados a la ley, mientras que en la ilegal, la situación se presenta al contrario, la ley se subordina a los gobernantes quienes legitiman su actuar a través de las aparentes decisiones que emite la asamblea ${ }^{13}$. De esta manera, la existencia de la politeia trae consigo misma la idea del Estado de derecho. En este tenor, Aristóteles concluye coherente y lógicamente, que en la democracia solo hay libertad, cuando esta última está sometida al derecho ${ }^{14}$. Vale aquí la pena, citar su pensamiento:

“Otra forma es aquella en la cual todos los ciudadanos no descalificados participan del gobierno, pero la soberanía corresponde a la ley. Otra, aquella en que todos participan de las magistraturas, con la única condición de ser ciudadanos, pero el poder supremo corresponde a la ley. Otra coincide en todo con ésta, excepto que el soberano es el pueblo y no la ley: esto tiene lugar cuando tienen la supremacía los decretos y no la ley. Y ocurre esto por causa de los demagogos. En las democracias de acuerdo con la ley no hay demagogos, sino que son los mejores ciudadanos los que tienen la preminencia, pero donde las leyes no tienen supremacía surgen los demagogos. Pues el pueblo se convierte en monarca, constituyendo uno con muchos, porque los muchos tienen el poder no como individuos, sino en conjunto" ${ }^{15}$.

Del pensamiento antes citado, se puede observar las dos formas en las que puede operar la democracia, por una parte está la legal (politeia), aquella en la que los individuos actúan conforme a la ley, donde ésta última es soberana, es decir, los individuos se deben de subordinar a ella, y por otra parte la demagogia, donde la ley se subordina a los individuos, porque éstos la pueden modificar en cualquier momento, es por ello que en este caso Aristóteles equipara al pueblo con un monarca que hace prevalecer sus determinaciones por encima de la ley.

Para dar solución a este conflicto, Aristóteles retomando el pensamiento de Solón, expuesto más de dos siglos antes, expone que es necesario realizar la distinción entre nomos y psefismata. Los primeros se refieren a las normas esenciales que caracterizan a la civitas, por lo que éstas deben de ser inalterables; por otra parte, los psefismata son las

\footnotetext{
12 RUIPÉREZ, J., op. cit., p. 5.

${ }^{13}$ Ibid., p. 6.

${ }^{14}$ Ibid., p. 10.

15 ARISTÓTELES, Política, 6 ${ }^{\mathrm{a}}$ ed., Centro de Estudios Políticos y Constitucionales, trad., Julián Marías y María Araujo, Madrid, 2005, libro, VI (IV), cap. 4,1, 291b, p. 176.
} 
resoluciones o decretos que el pueblo dicta en asamblea ${ }^{16}$. Lo anterior quiere decir, que los psefismata podían modificar la norma, siempre y cuando no fuera de las nomoi, ya que estas tienen que ser respetadas al ser consideradas la norma suprema de la polis. Indiscutiblemente la tesis planteada por el estagirita sigue vigente como inspiración de los gobernantes de los Estados constitucionales actuales, pues como lo manifiesta Ruipérez, haciendo alusión al pensamiento De $\mathrm{Vega}^{17}$, finalmente la historia del constitucionalismo nos muestra las diversas transformaciones que se han llevado a cabo para hacer reales y efectivas las ideas de libertad y democracia, mismas que ineludiblemente, convierten a los hombre en ciudadanos libres ${ }^{18}$.

El ideal político de la democracia desapareció del mundo Mediterráneo antes del comienzo de la era cristiana, pero mil años después, en el medievo, la democracia volvió a hacer su aparición en las ciudades-Estado italianas, cuando se transformaron así mismas en gobiernos populares, sin embargo, fueron retrocediendo en el curso del Renacimiento, toda vez que las ideas y prácticas democráticas y republicanas se sumergieron en regímenes imperiales u oligárquicos. En los casos anteriores los territorios eran considerablemente pequeños, situación que cambió en el siglo XVIII cuando surgen los grandes EstadosNación ${ }^{19}$.

En esta etapa histórica que se describe, es imprescindible abordar el pensamiento de Maquiavelo, quien de forma magnifica expone la relación entre democracia y libertad, que como ya se ha dicho son términos que se relacionan estrechamente; el florentino de manera clara resalta la idea de que no hay democracia sin libertad, como tampoco puede haber libertad sin democracia, planteamiento que lleva a Maquiavelo a sostener que el hombre solo sería realmente libre dentro de un sistema político en el que se articulen las ideas del vivere libero y vivere civile, lo cual es considerado por Pedro de Vega como un gran mérito ${ }^{20}$.

Ruipérez, explica las ideas de Maquiavelo, que éste a su vez retomó de Polibio, respecto al vivere libero y vivere civile, consideradas como la única forma en la que el hombre puede alcanzar la libertad dentro de un sistema político. El vivere libero, hace referencia al imperio de la ley, lo que conlleva a que los hombres serán libres efectiva y únicamente cuando obedezcan la ley ${ }^{21}$; para aclarar lo antes manifestado Ruipérez cita a Pedro de Vega:

"Sólo cuando las leyes son capaces de impedir que los intereses (económicos) particulares ... se impongan a la voluntad de otros individuos, es cuando tiene sentido

\footnotetext{
${ }^{16}$ RUIPÉREZ, J., op. cit., p. 7.

${ }^{17}$ Cfr. VEGA, P. DE, Mundialización y Derecho Constitucional: La crisis del principio democrático en el constitucionalismo actual, en Revista de Estudios Políticos (Nueve Época), núm. 100, abril-junio, Centro de Estudios Políticos y Constitucionales, Madrid, 1998.

${ }^{18}$ RUIPÉREZ, J., op. cit., p. 12.

${ }^{19}$ DAHL, R., La democracia y sus críticos (1989), trad. de Wolfson Leandro, Ediciones Paidos, Barcelona, 1992, p. 257.

20 Cfr. VEGA, P. DE, La democracia como proceso (Consideraciones en torno al republicanismo de Maquiavelo), Revista de Estudios Políticos, nº 120, 2003.

${ }^{21}$ RUIPÉREZ, J., op. cit., p. 24.
} 
proclamar que el respeto y el reconocimiento de la ley se identifica con el ejercicio de la libertad (con el vivere libero), pues de otra forma, los hombres sometidos a la voluntad de otros hombres, adquieren la condición de esclavos, al convertirse en meros instrumentos para que los más poderosos cumplan sus objetivos y satisfagan sus ambiciones” ${ }^{22}$.

De lo antes transcrito, se puede entender el pensamiento de Vega, en el cual se observar la innegable relación que existe entre, libertad, igualdad y democracia; viejas ideas que a su criterio únicamente pueden ser efectivas a través del Derecho Constitucional.

Siguiendo con la exposición del pensamiento de Maquiavelo, él comprendió que no era suficiente con el imperio de la ley para que la libertad de los hombres fuera realmente efectiva, para que tal situación se lograra, se necesitaba además de lo anterior, que las leyes que fueran obedecidas por los individuos hubieran sido elaboradas a través de la participación política de ellos mismos, a lo que se le denominó vivere civile ${ }^{23}$. Tiempo más tarde respecto a estas ideas, tanto Rousseau como Montesquieu, también sostenían que la libertad de los individuos solo sería realmente efectiva cuando se lograra conciliar la idea de libertad y democracia ${ }^{24}$.

Como una breve acotación, a lo largo de las líneas antes expuestas, se ha hablado de la relación recíproca entre libertad y democracia; pero después de todos estos planteamientos surge la pregunta, ¿qué es la libertad?, a lo que Montesquieu en su célebre obra De l'Espirit des Lois, responde: “es cierto que en las democracias parece que el pueblo hace lo que quiere; pero la libertad política no consiste en hacer lo que uno quiera ... La libertad es el derecho de hacer todo lo que las leyes permiten, de modo que si un ciudadano pudiera hacer lo que las leyes prohíben, ya no habría libertad, pues los demás tendrían igualmente esta facultad" 25 , de lo anterior, se puede observar como el concepto de libertad es profundo y no tan sencillo como pareciera ser, toda vez que éste comprende el hecho de que se es libre siempre que se actúa conforme a la ley, pero esa libertad se amplifica cuando en el cumplimiento de la ley se encuentra la convicción de hacerlo, es así, que en la democracia no todos hacen lo que quieren porque el actuar de los individuos se debe de encontrar dentro del marco legal.

En el pensamiento del barón de La Brède, sin duda alguna se encontraba la esencia del vivere libero de Maquiavelo, con el que también coincidía Rousseau, pero no así en cuanto al vivere civile. Por una parte Montesquieu parecía tener desconfianza hacia el pueblo, pues dentro de su postulado plantea la separación del pueblo de la toma de decisiones políticas fundamentales, es decir, que dentro de la organización del Estado, el pueblo no participara directamente en las decisiones, dicho de otra manera, hace referencia a la democracia representativa ${ }^{26}$.

\footnotetext{
${ }^{22}$ VEGA, P. DE, La democracia ..., p. 25.

${ }^{23}$ RUIPÉREZ, J., op. cit., p.30.

${ }^{24}$ Idem.

${ }^{25}$ MONTESQUIEU, Del espíritu de las leyes, trad. Mercedes Blázquez y Pedro de Vega, Tecnos, 4ª ed., Madrid, 1985, p. 106.

${ }^{26}$ RUIPÉREZ, J., op. cit., p. 31.
} 
Completamente contrario a este postulado, se encuentra lo sostenido por JeanJacques Rousseau, quien hablaba de la democracia de la identidad, donde el ciudadano es gobernante y gobernado a la vez, lo que significa que, los ciudadanos si participan directa y activamente en la vida política del Estado, tomando ellos mismos, sin intervención de representantes, las decisiones políticas fundamentales. Aunque posteriormente tuvo que aceptar la realidad de los Estados modernos, donde en atención a sus propias características, relativas principalmente al número de población y extensión territorial, es imposible que se lleve a cabo la democracia de identidad, por lo que la democracia representativa es la única opción ${ }^{27}$. Es verdad que el propio Rousseau se da cuenta de que en los Estados modernos la democracia directa es imposible, y que la elección de representantes se convierte en un mal necesario, que como tal hay que aceptar ${ }^{28}$.

Pero como lo dice Pedro de Vega, no obstante que Rousseau reconoce al final como única opción posible la democracia representativa, lo hace con la condición de que la actuación de los gobernantes se someta a dos cosas: a) primeramente, que los representantes no tengan un poder propio, de tal manera que sólo puedan hacer lo que expresamente el pueblo les permita (mandato imperativo), y b) lo que los elegidos decidan, debe ser siempre ratificado por el pueblo, sino es nulo, caso concreto la ley ${ }^{29}$.

Como se puede apreciar, en torno al ejercicio y gestión de la democracia, se han fijado diversas posturas; para poderlas comprender de mejor manera, es importante acotar los términos: soberanía, pueblo y representación; porque como también se expondrá en la última parte del presente texto, el no "entendimiento" (en el amplio sentido de la palabra) de estos términos, implica que se presenten divergencias entre la realidad política y jurídica; aunado a que juegan un papel sumamente importante dentro de los Estados constitucionales modernos.

\section{LA IDEA DE REPRESENTACIÓN POLÍTICA}

Para explicar la representación política, se partirá de la idea fundamental de que la soberanía reside en el pueblo, considerándose de tal manera a este último, como la fuente de todo poder público, dicha idea tomó fuerza conjuntamente con la evolución y expansión de los sistemas democráticos, impulsándose mayormente en Francia con los postulados de Rousseau; teniendo como consecuencia que a partir de ese momento se hayan precisado diversos pensamientos, así como creado y afinado diversas instituciones, lo cual no quiere decir que con anterioridad no se hubiera hablado de la soberanía, pues con ello sería no darles merito a los teólogos de la Edad Media, quienes ya hablaban de que la residencia de la soberanía se encontraba en la comunidad popular u olvidar como lo dice Carré de Malberg en su obra intitulada "Teoría del Estado", que: Hobbes en su postulado del absolutismo del príncipe, afirmaba que la masa de ciudadanos transfería al rey la potestad

\footnotetext{
${ }^{27}$ Ibid., p. 36.

${ }^{28}$ KRIELE, op. cit., p. 470.

${ }^{29}$ VEGA, P. DE, Legitimidad y representación en la crisis de la representación actual, en Institut de Ciènces Politiques i Socials, Barcelona, 1998, p. 19.
} 
que originalmente ostentaba ella; que Jurieu señalaba que la autoridad solo se encuentra en el pueblo; y que Locke fundó la sociedad civil en el consentimiento de sus miembros ${ }^{30}$.

No obstante lo anterior, la tesis de Rousseau proviene del concepto de que la soberanía, lo mismo que la sociedad y el Estado, tiene su génesis en un contrato ${ }^{31}$. Hace especial hincapié en que el hombre ha nacido libre y no puede renunciar a su libertad; y señala que "el hombre ha nacido libre y en todas partes se encuentra encadenado. Algunos se creen amos de los demás aun siendo más esclavos que ellos” ${ }^{32}$, planteamiento que invita a una reflexionar sobre la verdadera libertad del hombre y qué lo ahorrillo a ceder parte de ella, Rousseau sostiene que este problema se resuelve en el contrato social.

Como se aprecia, Jean-Jacques Rousseau manifiesta que la soberanía del pueblo es la base del contrato social, en este contexto, no puede ser alienada dado que el acto de delegación niega la esencia misma de la soberanía, entonces, el soberano no puede ser representado sino por sí mismo ${ }^{33}$; cuando el pueblo delega su poder efectivo, dirá, deja definitivamente de ser soberano ${ }^{34}$.

En este sentido, ya en una época actual inspirado en los grandes pensadores citados, Jorge Carpizo sostiene la idea de que la soberanía nacional presenta dos aspectos, el interno y el externo; el primero hace referencia a que el pueblo se otorga su propio orden jurídico, es decir, que por su voluntad decide libremente su forma de gobierno y elige a quienes van a ser sus representantes ${ }^{35}$. Como es bien sabido las Constituciones son producto de la voluntad del pueblo (el soberano) pues organizado en un Poder Constituyente da origen a la Ley Suprema de un Estado. El hecho de que el soberano opte por una forma de gobierno representativo, implica que a través de los instrumentos político-electorales que él mismo establece, se nombre a una persona o grupo de personas para que sean sus representantes, es precisamente esta facultad de decidir la que convierte al pueblo en soberano ${ }^{36}$.

En este orden de ideas, el aspecto externo implica la libertad de todas las naciones y la igualdad entre los pueblos, como se puede observar hace alusión a un aspecto internacional ${ }^{37}$, donde un Estado tiene relaciones con sus pares; en sí, la soberanía rige la vida interna de la nación y se proyecta hacia fuera en la vida internacional.

Con lo anterior y tomándolo sólo como punto de partida; queda claro que el titular de la soberanía es el pueblo y es ahí donde se debe de responder la siguiente interrogante,

\footnotetext{
30 CARRÉ DE MALBERG, Teoría General del Estado (1922), trad. de Fernando de Lión Depetre José, Facultad de Derecho/UNAM-Fondo de Cultura Económica, México, 1998, p. 875.

${ }^{31}$ Idem.

32 ROUSSEAU, J.-J., El contrato social o principios de derecho político (1762), trad. de Villaverde María José, Tecnos, Madrid, 1988, pp. 4, 14.

${ }^{33}$ ROUSSEAU, J.-J., El contrato ..., p. 106.

${ }^{34}$ VEGA, P. DE, Legitimidad y ..., p. 11.

35 CARPIZO, J., Desafíos Contemporáneos Del Derecho Constitucional. En Nuevos Estudios Constitucionales Porrúa, México, 2000, p. 261.

${ }^{36}$ SCHMITT, C., Teoría de la Constitución, Alianza Editorial, Madrid, 1982, p. 124.

${ }^{37}$ CARPIZO, J., op. cit., 2000, p. 262.
} 
¿qué es o quién es el pueblo? innegablemente es un elemento sine qua non para la democracia; se entiende como un ente real de personas con voluntad propia y singular ${ }^{38}$. Kelsen sostiene que la unidad del pueblo únicamente consiste en una ficción jurídica, toda vez que se encuentra fundado en la propia unidad del orden jurídico, es decir, existe una pluralidad de hombres que por sí mismos no se encuentran naturalmente unidos, la cual se logra mediante un orden normativo ${ }^{39}$. Por otra parte, Heller fue quien no quiso atribuir un significado especial al término pueblo, pues temía que se indujera a un error, confundiendo al pueblo con voluntad general, ya que esta no tiene contenido objetivo y su intención no era crear una utopía ${ }^{40}$. Para Sartori al término pueblo se le pueden atribuir seis referentes distintos de la palabra en el lenguaje político: todo el mundo, gran número de individuos, clase baja, totalidad orgánica, mayoría absoluta y mayoría limitada; lo que sustancialmente modifica la concepción de democracia como forma de gobierno ${ }^{41}$.

El pueblo naturalmente no es una unidad homogénea, ya que se encuentra conformado por una diversidad de hombres individuales que se encuentran regulados por un sistema jurídico, en este sentido, la representación del pueblo por el Parlamento es una simple ficción legal ${ }^{42}$. Asimismo, se encuentra fraccionado por diferencias nacionales, económicas, culturales, etcétera, lo que lleva a pensar que, en estricto sentido solo puede concebirse como una aglomeración de grupos sociales que se homogenizan a través de la norma jurídica, lo cual si es una realidad y no una simple ficción, pues los individuos solo pueden manifestar su voluntad política si se encuentran organizados, es así que en la democracia la voluntad se encuentra representada por la manifestación de muchos individuos que se encuentran relacionados legalmente, concluyendo esta idea en que la unidad del pueblo solo es posible como organización, es decir, como órgano jurídico ${ }^{43}$.

Entonces, el pueblo al ser el titular de la soberanía nacional, ¿cómo toma decisiones en los Estados modernos?; como se ha dicho, el pueblo es una ficción jurídica y política, que para que pueda tener voz es necesario que haga uso de la figura de la representación, misma que a continuación se analiza.

Jellinek señala que genéricamente la representación es la relación de una persona con otra o varias, en virtud de la cual, la voluntad de la primera se considera como expresión inmediata de la voluntad de la última, de suerte que jurídicamente aparecen como una sola persona. Por lo anterior, el sistema representativo es altamente criticado, al cual, hasta cierto punto se le considera engañoso, en virtud de que en éste, tienen que convivir conceptos del mundo jurídico y hechos reales ${ }^{44}$. Es así que en el pueblo, entendido como un conjunto de individuos jurídicamente organizados, como el soberano del Estado y voluntad general, no pueden estar integradas voluntades particulares que instruyan a sus

38 FERNÁNDEZ-MIRANDA CAMPOAMOR, A., Sistema electoral, Partidos Políticos y Parlamento, Colex, Madrid, 2003, p. 32.

${ }^{39}$ KELSEN, H., Teoría General ..., p. 249.

${ }^{40}$ CARPIZO, J., La Constitución Mexicana de 1917, 14 a ed., Porrúa, México, 2004, p. 173.

${ }^{41}$ SARTORI, G., op. cit., p. 41.

${ }^{42}$ KELSEN, H., Teoría General ..., p. 510.

${ }^{43}$ KELSEN, H., Esencia y valor..., p. 20.

44 JELLINEK G., Teoría General del Estado, trad. de los Rios Fernando, Editorial Comares, Granada, 2000, pp. 559-560. 
representantes, por tal motivo, en la correcta representación política, el representante no solo representa la voluntad particular de quien lo envía, sino de todo el pueblo ${ }^{45}$.

El régimen representativo, llega a ser hoy en día el tradicional, donde constitucionalmente el pueblo se gobierna por medio de sus elegidos, y ello en oposición, tanto al régimen del despotismo, en el que el pueblo no tiene ninguna acción sobre sus gobernantes. Además implica solidaridad y armonía entre gobernantes y gobernados; a los elegidos se les nombra solo por un tiempo limitado ${ }^{46}$.

Carré de Malberg señala que para Montesquieu el régimen representativo, tiene de fondo un régimen aristocrático, en virtud de que su planteamiento indica que los representantes se deben de elegir entre los ciudadanos más dignos de convertirse en agentes de ejercicio del poder. Por otra parte, existen diversas formas de designación de representantes, por ejemplo: en los Estados dónde se practica la aristocracia nobiliaria, el criterio de designación es la filiación. En otros Estados la designación resulta de la edad, el grado de riqueza, de la profesión o demás presunciones de aptitud del mismo género. Es así que, en los Estados con tendencias democráticas se parte de la idea de que el mejor modo de discernir a los ciudadanos más capaces es a través del sufragio universal ${ }^{47}$, que se expresa en las elecciones, entendidas como el conjunto de procedimientos, capaces de garantizar la expresión libre e igual de todas las voluntades individuales, y de canalizarlas hacia la formación transparente de las decisiones colectivas ${ }^{48}$; una vez electos los representantes, su actuar cuenta con límites, establecidos en el orden jurídico normativo ${ }^{49}$.

En un Estado democrático, el pueblo debe de estar jurídicamente organizado para poder expresar su voluntad y de tal manera se considere como una unidad que tiene el carácter de órgano, cuya voluntad se manifiesta en el Parlamento, es así, que el pueblo y Parlamento forman una unidad jurídica, en otras palabras, el pueblo se organiza jurídicamente mediante el Parlamento ${ }^{50}$. En este sentido, se tiene que puntualizar, que el pueblo como órgano primario participa en la elección de sus representantes, cuya intervención no concluye aquí, en virtud de que también nace una relación permanente entre el representante y el pueblo en su unidad, aun cuando no exista una garantía segura de que el órgano del pueblo represente de una manera políticamente acertada la voluntad general. No obstante lo anterior, los mecanismos políticos de consumo hacen que la voluntad de un parlamento que se desvinculó de la realidad y necesidades del pueblo, no dure largo tiempo fuera de la autoridad de él, pues las legislaturas tienen un duración de periodo, es posible la disolución de las Cámaras por el gobierno, existe el sufragio y más allá de los medios políticos, también se puede hacer uso de mecanismos jurídicos, que en cierta medida aseguren la representación del pueblo como órgano de la voluntad del mismo $^{51}$. Como se puede observar en el Estado existe un órgano primario que es el pueblo

\footnotetext{
${ }^{45}$ Ibid., p. 568.

${ }^{46}$ CARRÉ DE MALBERG, Teoría General del Estado (1922), trad. de Fernando de Lión Depetre José, Facultad de Derecho/UNAM-Fondo de Cultura Económica, México, 1998, pp. 916-917.

${ }^{47}$ Ibid., p. 922.

${ }^{48}$ BOVERO, M., Los desafíos de la democracia, Editorial UBIJUS, México, 2013, p. 56.

${ }^{49}$ KELSEN, H., Teoría Pura ..., p. 35.

${ }^{50}$ JELLINEK G., op. cit., p.575.

${ }^{51}$ Ibid., pp. 577-578.
} 
y que delega funciones en el Parlamento; el pueblo organizado en Parlamento, lo que significa que el pueblo es representante y representado.

En este orden de ideas, Hobbes emplea el concepto de representación para justificar la obligación política de los gobernados hacia el soberano de legitimar la autoridad de este último, asimismo, Carré de Malberg afirma que lo que se encuentra en el régimen representativo no es un sistema de representación personal, sino precisamente un sistema de organización de voluntad y de la persona nacional ${ }^{52}$.

Una expresión más de la representación política se encuentra en El Federalista de Madison, Hamilton y Jay, quienes la entienden como un sustituto ideal de la democracia directa en países con grande extensión y que las instituciones representativas lo deben de ser de personas y no de intereses ${ }^{53}$. Respecto a lo anterior Hanna Pitkin señala: "Madison concibe la representación como una manera de concentrar un conflicto social peligroso en un foro central único, donde puede ser controlado por la vía del equilibrio y del bloque” ${ }^{4}$, afirmando que la representación política se refiere a individuos que actúan en un sistema representativo institucionalizado, por lo que sus acciones se vuelven representativas ${ }^{55}$. "Los Federalistas", atendiendo a las ideas de Montesquieu sobre la división de poderes, asumieron que el hecho de concentrar el poder en un solo órgano representante podría ocasionar que fácilmente se abusara de él, pues como bien lo señalaba Montesquieu en su obra De l'Espirit des Lois, "Para que no se pueda abusar del poder es preciso que el poder frene al poder". Tal planteamiento se relaciona con el pensamiento de Locke, quien destacaba la importancia de que el poder supremo, representado por el poder legislativo, tuviera una serie de mecanismos de control para respetar los derechos y libertades inalienables ${ }^{56}$.

John Stuart Mill, en sus Consideraciones sobre el gobierno representativo, unifica las ideas de Madison, Beentham ${ }^{57}$ y Pitkin, aseverando que "un gobierno representativo, cuya extensión y poder están limitados por el principio de libertad (...), constituye una condición fundamental para la existencia de comunidades libres y de una prosperidad deslumbrante" $^{58}$. Precisamente fue Stuart Mill, quien retomó la idea de Madison manifestando que, es importante que el electorado designe a un representante que sea más instruido que ellos y con un sentido de responsabilidad. Este individuo virtuoso, el representante, debe actuar de manera libre según el crea conveniente, sin presiones o condicionantes, pero por otra parte, el electorado tiene el derecho de saber cómo piensa obrar y según a las opiniones emitidas se propondrá un actuar en el deber público ${ }^{59}$.

\footnotetext{
${ }^{52}$ CARRÉ DE MALBERG, op. cit., p.77.

${ }^{53}$ HAMILTON, A., MADISON J. y JAY, J., El Federalista, Fondo de Cultura Económica, 2a ed., México, 1957, p. 123.

${ }^{54}$ PITKIN, H., The concept of representation, University of California Press, Berkeley, California, 1967, p. 195, disponible en http://mavdisk.mnsu.edu/parsnk/Linked\%20Readings/Pol321/pitkin.pdf, consultado el 04 de julio de 2017.

${ }^{55}$ Ibid., p. 212.

${ }^{56}$ LOCKE, J., Segundo tratado sobre el gobierno civil, Alianza, Madrid, 1996, p.251.

57 BEETHAM, D. y BOYLE, K., Introducing Democracy. 80 Questions and Answers, UNESCO, Francia, 1995, p. 48.

${ }^{58}$ HELD, D., Models of Democracy, Stanford University Press, Standford, California, 1987, p. 89.

${ }^{59}$ STUART MILL, J., Del gobierno representativo, Tecnos, Madrid, 1985, pp. 140-145.
} 
Las ideas expuestas por Madison se sustentaron en el pensamiento de Locke, quien dijo un siglo antes, que la autoridad del gobierno se encontraba limitada en sus propósitos y en cualquier momento podía ser revocado, si en el ejercicio de sus funciones se excedía; planteamiento que se desprende de una corriente ius naturalista, toda vez a que también hace alusión a que ningún individuo puede tener más poder que el que poseía cuando vivía en estado de naturaleza aunque se lo haya transferido los miembros de la sociedad, y Madison abona: "nadie puede transferir a otro un poder superior al que él mismo posee, y nadie posee poder arbitrario absoluto sobre sí mismo ni sobre otra persona” ${ }^{60}$.

Precisamente sobre esa idea de la revocación de mandato, Pedro de Vega retoma al constitucionalismo socialista, dónde se produce la idea de Lenin, presa en el Decreto de 2XII- 1917, donde se señala que, "Toda institución electiva, o asamblea representativa, solo puede ser considerada realmente democrática y representante efectiva de la voluntad popular si se reconoce y aplica el derecho de los electores a revocar a sus elegidos” ${ }^{\text {}}$.

A lo anterior se puede añadir que, la representación se vuelve democrática, cuando además de actuar por cuenta y a nombre de otros, en este ejercicio se reproduce la voluntad e intereses de los ciudadanos. El grado democrático dentro de la representación, depende de la capacidad que se tenga para que dentro de los procesos representativos de manera efectiva el representante traslade la voluntad de los representados al momento de tomar decisiones $\mathrm{u}$ opiniones políticas, el ser $\mathrm{o}$ no democrático, no se determina del distanciamiento o cercanía que existe entre el representante y el representado, ni de lo vinculante que pueda ser el mandato entre estos sujetos ${ }^{62}$.

\section{EL PARLAMENTARISMO: MANDATO IMPERATIVO Y REPRESENTATIVO}

A lo largo de la historia, desde sus orígenes y durante su evolución, se ha relacionado la figura del Parlamento con la de la representación política, toda vez que, no se puede hablar de él sin ésta última. Los orígenes de las Asambleas parlamentarias se encuentran en la Europa medieval dentro de los siglos XII y XIII, en Inglaterra surge como un órgano integrado por nobles y cargos eclesiásticos, más tarde, convocados por Simón de Mofort en 1265 y por Eduardo I en 1295, se integraron representantes de condados y burgos para recabarles asistencia económica ${ }^{63}$.

Como se observa y puntualiza Pedro de Vega, la representación de los parlamentos medievales se construyó sobre la base del derecho privado, en virtud de que se definían perfectamente por una parte, los sujetos de la representación, y por otra, la extensión y

\footnotetext{
${ }^{60}$ HAMILTON, A., MADISON, J. y JAY, J., op. cit., p. 150.

61 VEGA, P. DE, Significado constitucional de la representación política, en Rubio Núñez, Rafael (ed.), Obras Escogidas De Pedro De Vega, Centro de Estudios Políticos y Constitucionales, Madrid, 2017, p. 403.

${ }^{62}$ GREPPI, A., La democracia y su contrario, Editorial Trotta, Madrid, 2012, p. 44.

63 ABELLÁN, Á.M., Notas sobre la evolución del parlamento y de la representación política, Revista de Estudios Políticos, nº 92, 1996, p. 163.
} 
contenido de la misma ${ }^{64}$, lo que significa que, el representante claramente operaba a nombre de una persona o personas determinadas. De acuerdo con Pedro de Vega: "Para la teoría política medieval, esa universitas, se entenderá únicamente representada por el señor tum entre el monarca y el pueblo, en maior populo o maior principe” ${ }^{65}$.

En este sentido, la representación en el parlamento era una relación civil, del derecho privado, y no político, lo que implicaba que el representante respondiera directamente a su mandante y obviamente a intereses particulares, situación que llevó al parlamento en sus orígenes a no ser un representante de la voluntad general; respecto a lo anterior, Carré de Malberg dice:

"En primer lugar, el diputado al cuerpo legislativo nada puede emprender por su propia iniciativa, sino que, como simple mandatario, ha de actuar y votar en la asamblea según las instrucciones imperativas que le han sido dadas por sus electores; tal es el origen del sistema llamado del mando imperativo. En segundo lugar, la ley, incluso elaborada en estas condiciones, no es aún perfecta”,66.

Cómo ha quedado citado, esta técnica de representación se concibió como mandato imperativo, y tuvo vigencia durante varios siglos en Inglaterra así como en los parlamentos medievales del continente, posteriormente sería sustituido en los procesos revolucionarios burgueses por la fórmula del llamado mandato representativo; dejando así de lado al mandato civil, que como se ha dicho, a través de él, únicamente se representaban intereses de unos cuantos, y si no se ejercía correctamente, como cualquier poder otorgado de particular a particular, se podía revocar.

La representación fundada en el mandato imperativo presentaba grandes inconvenientes, pues no todos tenían la posibilidad de tener un representante en el parlamento. Situaciones como ésta, motivaron a que en Inglaterra se optara por el mandato representativo, ideas que más tarde se hicieron notar sobresalientemente en el proceso revolucionario francés, pues no solamente se empleó como elemento técnico, sino que el modelo de la democracia representativa se colocó frente a los sistemas políticos Antiguos, y no como en Inglaterra, que se había catalogado solamente como una simple evolución de la democracia en cuanto a su funcionalidad ${ }^{67}$.

Para Kelsen el parlamento debía operar de manera independiente al pueblo, dejando de lado al mandato imperativo, lo que significa que los diputados debían funcionar de manera independiente, es decir, sin recibir órdenes directas de sus mandatarios, ósea que, el represéntate funciona jurídicamente independiente al pueblo. Paradójicamente para Kelsen, en la democracia representativa quien legisla no es el pueblo, sino el parlamento; en este tipo de democracia el cuerpo electoral organizado (pueblo), es sólo un órgano de

\footnotetext{
${ }^{64}$ VEGA, P. DE, Significado constitucional de la representación política, en Rubio Núñez, Rafael (ed.), Obras Escogidas De Pedro De Vega, Centro de Estudios Políticos y Constitucionales, Madrid, 2017, p. 403. ${ }^{65}$ Idem.

${ }^{66}$ CARRÉ DE MALBERG, op. cit., p. 919.

${ }^{67}$ Ibid., p. 405.
} 
creación ${ }^{68}$. Pensamiento que señala como ficción, la relación jurídica que se presenta entre el pueblo y el parlamento, sin perjuicio de la representación política.

Con la figura de la representación, aparecen en la escena política, los partidos, sindicatos y asociaciones, instituciones que vienen a trastocar las formulaciones del mandato representativo, en atención a que el interés nacional común se ve fragmentado en intereses sociales antagónicos, que se canalizan a través de los partidos; entonces, de acuerdo con Pedro de Vega surge un dilema:

“O bien se sigue insistiendo en el viejo concepto de representación, lo que supone ignorar la realidad de los partidos, o bien se asume la existencia de los partidos, lo que implica el obligado paso de lo que Duverger ha denominado el tránsito de una concepción individualista a otra comunitaria de representación... el problema dista de haber quedado resuelto en el constitucionalismo del presente. Es verdad que los partidos políticos no son ya realidades ignoradas en las Constituciones más modernas... Sin embargo, no es menos cierto, que junto a la incorporación y al reconocimiento legal de los partidos, esos mismos ordenamientos constitucionales continúan manteniendo la figura del mandato representativo" 69 .

El dilema que se señala en relación a los partidos políticos lleva a formular una interrogante respecto a qué es lo que pasa con los diputados ¿representan a su partido o al pueblo que los eligió mediante el sufragio?, la respuesta puede resultar obvia pero controvertida para el ámbito político y jurídico; si representan intereses de su partido entonces se estaría hablando de un mandato imperativo y no representativo. En el siguiente numeral, se desarrollará de manera un poco más amplia la presente respuesta.

Para concluir este apartado, es pertinente acotar las diferencias entre el mandato imperativo (lo ejerce un mandatario) y el mandato representativo (lo ejerce un diputado), lo cual se realiza a través del pensamiento de Carré de Malberg, quien señala que básicamente existen cuatro diferencias primordiales: I) el mandato imperativo como todo acuerdo contractual, únicamente surte efecto entre las partes que lo realizaron, justificación bastante para que el mandatario únicamente represente los intereses de quien lo nombró, mientras que el diputado, representa a toda la nación (situación que se plasmó en la Constitución francesa de 1789); II) El mandato es revocable a voluntad del mandante, en cualquier tiempo, a diferencia de que en él régimen representativo, en ningún caso los electores pueden revocar a su diputado, salvo lo que ocurre en países con democracia directa como en los pequeños cantones suizos; III) naturalmente el mandatario rinde cuentas a su mandante directo y directamente es responsable de sus actos con él, por otra parte, el diputado no rinde cuentas directas a sus votantes; IV) el mandatario únicamente ejerce las funciones que le confirió su poderdante, por ello todo lo que realice fuera de ellas es nulo; de tal forma, el diputado no se puede someter a sus electores, porque no

\footnotetext{
${ }^{68}$ KELSEN, H., Teoría General ..., p. 514.

${ }^{69}$ VEGA, P. DE, Significado constitucional ..., p. 410.
} 
podría emitir decisiones distintas a las que le encomendaron y de ser así, no quedarían obligados a las decisiones de la asamblea ${ }^{70}$.

Finalmente, se tiene que decir que las democracias modernas sólo se pueden entender a través de la existencia de partidos políticos y dependen de si el parlamento es un instrumento útil, es decir, si éste último resuelve las exigencias sociales. Kelsen sostiene que en los Estados modernos la única forma de implementar la democracia es a través del parlamentarismo, por lo que el fallo en el parlamentarismo implica un fallo en la democracia $^{71}$. Cabe entonces mencionar aquí las excelentes palabras de Javier Ruipérez, "la democracia no está y nunca estará en crisis, quien está en crisis, son sus gestores”72.

\section{REALIDAD JURÍDICA Y POLÍTICA EN LA REPRESENTACIÓN}

En este último apartado, realizando un ejercicio de carácter deductivo-inductivo sobre lo que se ha expuesto con anterioridad; partiendo desde la conceptualización, origen y evolución de la democracia, y pasando a través de lo que se ha dicho sobre soberanía, pueblo, representación, parlamento, mandato imperativo y mandato representativo; se pretende hacer una reflexión sobre la realidad innegable que se vive en la gran mayoría de sistemas democráticos representativos, y poder así, señalar algunas problemáticas que se generan en torno a ella.

En este contexto, se tiene que admitir que en las democracias modernas, la representación solo se puede canalizar a través de los partidos políticos en el parlamento, negar su existencia y olvidarlos sería más que una injusticia histórica una solemne necedad $^{73}$; toda vez que en algunos Estados ya se plantea, e incluso es una realidad, la idea de que los representantes sean independientes a los partidos políticos, lo cual lleva a pensar, que no se ha aprendido de las experiencias de que cuando desaparecen los partidos políticos, como lo dice De Vega, los que les sustituyen son los grupos de presión, los magnates de las finanzas o los demagogos con vocación de dictadores ${ }^{74}$.

Aunque los partidos políticos sean necesarios, el problema surge cuando, en lugar de ser simples intermediarios, que traducen a nivel estatal la voluntad política de la sociedad, se convierten en muros de separación, dando pleno sentido, a aquella vieja afirmación de James Bryce de que "la organización traiciona siempre la voluntad del pueblo"75. Para Loewenstein, desde la aparición de los partidos políticos, el mandato imperativo se ha convertido en un fenómeno común, ya que el representante está sujeto a una disciplina más o menos estricta, que lo obliga a votar según las decisiones de liderazgo del partido político al que pertenece ${ }^{76}$, aún en contra de la voluntad nacional. No obstante

\footnotetext{
${ }^{70}$ CARRÉ DE MALBERG, op. cit., 1998, pp. 925-928.

${ }^{71}$ KELSEN, H., Esencia y valor ..., p. 36.

72 RUIPÉREZ, J., Vigencia y reforma de la Constitución española de 1978, en Encuentro: La Constitución de 1978: 40 años, en Club Financiero Atlántico, La Coruña, 19 de noviembre de 2018.

${ }^{73}$ VEGA, P. DE, Legitimidad y representación ..., p. 14.

${ }^{74}$ Ibid., p. 19.

${ }^{75}$ BRYCE, J., Constituciones flexibles y constituciones rígidas, Centro de Estudios Constitucionales, Madrid, 1988, p. 98.

${ }^{76}$ LOEWENSTEIN, K., Teoría de la Constitución, 4ª reimpresión, Ariel, Barcelona, 1986, p. 333.
} 
lo anterior, en estos no debe de recaer culpabilidades que no tienen, y se les catalogue como destructores del sistema de principios y creencias en las que el Estado liberal cimentó la legitimidad política de la democracia representativa ${ }^{77}$. Obviamente, siempre se debe tener presente que los partidos políticos deben de aglutinar los intereses comunes, los cuales constituyen las directrices e ideología política de los mismos, para llegar al poder e implementar un programa de gobierno determinado que satisfaga el bien común y responda a los intereses generales. Es por ello, que al hablar de democracia de una manera institucional, se tiene que hacer a través del sistema de partidos ${ }^{78}$.

Ahora bien, no hay que dejar de lado a los diputados, Sieyès decía: "El pueblo solo puede tener una voz: la voz de la legislatura nacional. Los comitentes solo pueden hacerse oír por medio de los diputados nacionales; el pueblo solo puede hablar, solo puede actuar a través de sus representantes"79, sin embargo los diputados han olvidado la esencia del mandato representativo que se les ha conferido, circunstancias que de alguna manera o en cierto grado, han propiciado los poderes privados para imponer su voluntad y lograr sus aspiraciones, hechos que no deberían de acontecer, porque en el sistema constitucional democrático ningún poder debería de ser un poder factico, es decir, como refiere Bovero, cualquier poder debería ser regulado y limitado, no solamente los poderes públicos, sino también los poderes privados ${ }^{80}$.

Con lo anterior, parece ser que el hablar de mandato representativo en una situación donde los diputados obedecen órdenes y rinden cuentas a su partido, donde los partidos condicionan y disciplinan la actuación parlamentaria de los diputados, donde éstos dependen de sus grupos parlamentarios a la hora de la votación, donde están subordinados a la maquinaria partidista en el momento en el que se confeccionan las listas electorales, donde existen dudosas sanciones a los diputados indisciplinados, donde hay un sometimiento real de los diputados al partido al que pertenece ${ }^{81}$; y continuar sosteniendo que los representantes lo son de toda la Nación y no de intereses particulares, equivaldría a mantener un concepto de representación y democracia representativa, que forma parte ya de la arqueología constitucional, señalamiento que Pedro de Vega retoma de Morstein-Marx ${ }^{82}$.

Ante estas circunstancias, el Parlamento deja de ser el órgano donde se discuten ideas para hallar la verdad y justicia, ha perdido incidencia política y significado institucional; se ha convertido en un lugar de ratificación, donde se busca el aplauso, tan es así que los discursos se dirigen no para convencer a los diputados que piensan diferente a ellos, sino a la ciudadanía activa ${ }^{83}$. Es en esta parte, donde los medios de comunicación tradicionales (sin contemplar por ahora el uso de internet y redes sociales, que bien valdría la pena abordar, pero de manera separada) juegan un papel trascendente y decisivo,

\footnotetext{
77 VEGA, P. DE, Legitimidad y representación ..., p. 16.

${ }^{78}$ GONZALES ROMERO, E., El sistema de partidos en México, Convergencia, México, 2006, p. 3.

${ }^{79}$ SIEYÈS, E.-J., ¿Qué es el Tercer Estado? ensayo sobre los privilegios, Alianza, Madrid, 1989, p. 170.

${ }^{80}$ BOVERO, M., op. cit., p. 57.

${ }^{81}$ VEGA, P. DE, Significado constitucional ..., p. 411.

${ }^{82}$ VEGA, P. DE, Legitimidad y representación ..., pp. 14-15.

${ }^{83}$ VEGA, P. DE, Supuestos históricos, bases sociales y principios políticos en el Derecho Constitucional democrático, en Rubio Núñez, Rafael (ed.), Obras Escogidas De Pedro De Vega, Centro de Estudios Políticos y Constitucionales, Madrid, 2017, p. 164.
} 
principalmente en aquellos Estados donde la democracia no se encuentra bien consolidada, en atención a que son quienes construyen la opinión pública de masas, manipulando la opinión racional y libre. Por esta razón, Pedro de Vega sostiene que la opinión pública para que sea considerada racional y libre, debe de ser la de los mejores, la de la élite, postura que abraza en definitiva las concepciones ilustradas, del gobierno del pueblo, pero sin el pueblo $^{84}$. Aunque tal afirmación es difícil que acontezca, en atención a que muy probablemente la generalidad lo aceptaría, aprobaría o reconocería, lo que trae aparejado como resultado que, cualquier intento por recobrar las viejas ideas liberales resulte fallido.

La relación existente entre los diputados y el partido político al que pertenecen se ha vuelto compleja, y difícil de regular, en atención a que fácticamente hacen que se confronte el mandato representativo con el mandato imperativo, partiendo desde el hecho de que, el diputado obedece a un mandato de partido y no al otorgado por el pueblo, razón suficiente para concluir que incluso la titularidad de los escaños corresponde a los propios partidos políticos, como lo refiere de Vega "De hecho, en la praxis parlamentaria de los países, se comprueba cada día la efectividad de este aserto. Son los partidos y los grupos parlamentarios quienes condicionan y determinan de una manera absoluta en la conducta de los Diputados" ${ }^{85}$.

Lo cierto es, que los diputados al actuar de esta manera, están contraviniendo la prohibición constitucional del mandato imperativo, pues el reconocimiento jurídico de la libertad absoluta, implica que la titularidad de los escaños sea de una persona y no del partido; pero como bien lo puntualiza Pedro De Vega, el problema no consiste en determinar quién es el titular de los escaños, sino en analizar la validez de los procedimientos sancionadores (ejecutados muchas veces en un auténtico fraude de ley) que aplican los partidos políticos a los diputados, cuando colisiona la realidad jurídica de estos últimos con las prácticas partidistas ${ }^{86}$. Con lo anterior, el mandato representativo pasa a formar parte de la retórica constitucional, al prevalecer la realidad política sobre la realidad jurídica, con ello no se rompe el orden constitucional, sino lo que ocurre, da lugar a las mutaciones constitucionales. Jorge Carpizo las definen como la modificación no formal del Ordenamiento Constitucional, como aquellos cambios operados en el mismo conjunto normativo, sin seguir el procedimiento de la reforma constitucional. La importancia de la mutación constitucional según lo expuesto por Wong Meraz, se encuentra en que a la vez que se respeta la letra y aún el espíritu de la Constitución, se logra adaptar la Ley Suprema a la realidad política cambiante; así el ordenamiento político constitucional no se quebranta, se facilita su modificación, y con ello se resuelven eficaz y rápidamente las exigencias político-sociales $^{87}$.

El problema de la representación que se plantea en párrafos anteriores, crea una situación fuera de lo previsto por el derecho constitucional, en atención a que queda claro el hecho de que voluntariamente los diputados aceptan como normal el sometimiento de sus decisiones y actuar a los partidos políticos, lo que significa que no se puede imputar

\footnotetext{
${ }^{84}$ Ibid., pp. 166-167.

${ }^{85}$ VEGA, P. DE, Significado constitucional ..., p. 412.

${ }^{86}$ Ibid., p. 413.

${ }^{87}$ WONG MERÁZ, V.A., Constitución mexicana. Reforma y mutación, Porrúa, México, 2010, p. 15.
} 
jurídicamente la violación al mandato representativo, toda vez que de alguna manara se encuentran en el ejercicio de la libertad que éste le confiere. Pero qué es lo que pasa cuándo no hay un sometimiento voluntario del diputado hacia el partido, evidentemente al presentarse una confrontación entre ambos, prevalecería la voluntad del diputado, en el entendido de que el principio clásico de representación es el que se encuentra constitucionalmente regulado y obviamente aceptado, no así, el mandato imperativo que pretendieran hacer valer los partidos ${ }^{88}$.

El sometimiento voluntario del diputado, también implica que lo sea respecto de la disciplina parlamentaria que impone el partido, y es ahí donde de nueva cuenta se genera otro conflicto, toda vez que, los partidos políticos recurren a medios como las dimisiones en blanco, multas, sanciones, etcétera, con el propósito de mantener la disciplina e impedir que se produzcan conflictos ${ }^{89}$. No cabe duda que las dimisiones en blanco exigen una referencia especial, por su generalización e importancia, toda vez que son un fenómeno innegable en la realidad política y constitucional, que con el paso de los años, se fue haciendo más frecuente en las democracias representativas, pues la firma en blanco de la renuncia al escaño, desde el momento en el que es proclamado candidato, es una herramienta que los partidos políticos utilizan para imponer su voluntad, y con ello si es necesario, poder prescindir del diputado incomodo o de un conflicto ${ }^{90}$.

\section{Pedro de Vega menciona:}

“Ahora bien, la cuestión no estriba en explicar el origen, las causas y la amplitud del fenómeno, sino en descifrar su verdadero sentido y alcance jurídico. Dicho en otros términos: ¿Qué valor jurídico tiene la dimisión en blanco y sin fecha entregada al partido para que la utilice o no según sus conveniencias? ¿Puede efectivamente considerarse la dimisión en blanco un instrumento que jurídicamente permita a los partidos prescindir de los diputados incomodos? ${ }^{91}$.

Si se pretendiera responder desde un aspecto estrictamente positivista a las interrogantes que se han citado, se diría que las dimisiones en blanco no son válidas, en virtud de que sencillamente dentro de la Constitución no se encuentran contempladas, aunado a que todo acto contrario a la ley es nulo; el propio Pedro de Vega, entre otras palabras, tajantemente también señala que las dimisiones en blanco a la luz de la ley son ilícitas. Hay que recordar que éstas se firman como una expresión de voluntad del diputado hacia el parlamento, en el que el primero renuncia a un escaño ${ }^{92}$; en este entendido, aparentemente los partidos políticos no intervienen, sino que únicamente tienen la función de transmitir el mensaje, porque son ellos quienes desde un inicio, son los tenedores de la dimisión. Una vez que el partido político entrega la dimisión en blanco al parlamento, pueden presentarse dos supuestos: que el diputado reconozca el documento y no se oponga, entonces, la dimisión en blanco causa plenos efectos jurídicos; o que el diputado, exprese

\footnotetext{
${ }^{88}$ VEGA, P. DE, Significado constitucional ..., p. 414.

${ }^{89} \mathrm{Idem}$.

${ }^{90}$ Idem.

${ }^{91}$ VEGA, P. DE, Significado constitucional ..., p. 415.

${ }^{92}$ Idem.
} 
su voluntad de continuar como parlamentario, lo que evidentemente implica que la renuncia no surta efectos. Al respecto, Pedro de Vega emite una conclusión, que él mismo califica como paradójica, "Las dimisiones en blanco pueden tener validez jurídica si el diputado dimisionario no denuncia con anticipación con un acto de voluntad en contra el carácter ficticio de la dimisión"93, por lo que se puede decir que el cumplimiento y validez de la dimisión, al no ser coercible, únicamente queda como deber de conciencia del diputado, aunque también, ésta debe de ser aprobada por la asamblea ${ }^{94}$.

La complejidad y compromiso que implica el ejercicio de la democracia representativa ha llevado a que diversos Estados introduzcan en su régimen político electoral, mecanismos de participación directa o mejor dicho, de democracia semidirecta, porque como lo señala Maurice Duverger, operan dentro de sistemas predominantemente representativos $^{95}$, pero éstos como dice Pedro de Vega, solamente se han encargado de demostrar, principalmente en aquellos Estados con una mínima consolidación democrática, que siempre acaban convirtiéndose en “ensayos mortecinos y frustrantes”, siendo así solamente una "democracia de entrenamiento"; y también señala “...y como a todos los mitos que se introducen en el mundo de la política, quizá lo mejor que se puede hacer con la idea de democracia participativa es no hablar siquiera de ella, y aplicarle aquellas palabras del Virgilio, non ragioniam di lor, ma guarda e passa"96 (no hablemos de ello, miremos y pasemos).

\section{CONCLUSIONES}

A manera de conclusión se puede decir que, el ejercicio y gestión de la democracia, desde sus orígenes en Grecia hasta la actualidad, ha evolucionado de manera conjunta con la sociedad y el Estado. En este sentido, resulta importante mencionar que su estudio no debe radicar solamente en su conceptualización, sino en mayor media, en el cómo ésta puede ser eficaz; cierto es que el primer punto ha quedado resuelto históricamente a través de diversos postulados, pero el tema de cómo lograr la eficacia de la democracia está siempre vigente, pues cada Estado posee sus propias condiciones, sociales, políticas y/o culturales, cambiantes, lo cual no permite que los mecanismos políticos y electorales que se emplean en una democracia eficaz (si es que alguna se puede considerar así), se empleen en cualquier Estado de manera general.

Ahora bien, se debe tener siempre presente que la democracia, libertad e igualdad son conceptos que sin duda alguna se encuentran política y jurídicamente entrelazados; situación que permite afirmar que, no hay libertad sin democracia y democracia sin libertad; es así, que estas ideas se deben de estudiar en conjunto y no de manera aislada.

Por otra parte, y también a modo de conclusión, se puede señalar que las democracias modernas, sólo se pueden entender a través de la existencia de partidos

\footnotetext{
93 Ibid., p. 416.

${ }^{94}$ CARRÉ DE MALBERG, op. cit., p. 919.

95 DUVERGER, M., Institutions politiques et droit constitucionnel, Press Universitaires de France, París, 1955, p. 93.

${ }^{96}$ VEGA, P. DE, Legitimidad y representación..., p. 33.
} 
políticos y de la existencia del mandato representativo en el parlamento. Desafortunadamente, en muchos Estados que se consideran democrático-representativos, los partidos políticos se han convertido en grupos de elite que se rotan el poder, donde se velan intereses particulares y no generales, que para poder acceder se necesita del apoyo de alguien que ya está dentro, y la posibilidad de cualquier ciudadano de ser un candidato para ocupar un cargo público, se vuelve casi nula. En este tenor de ideas, los partidos políticos se han alejado de la realidad social dejando de ser intermediarios entre el pueblo y el gobierno, preocupándose únicamente por competir entre ellos y no en su obligación que tienen para con el pueblo, provocando que se genere una gran brecha entre la realidad jurídica y política, lo cual no necesariamente rompe el orden constitucional, toda vez que se pueden conciliar mediante las mutaciones constitucionales o la reforma constitucional, recordando que son el mecanismo y garantía para que la Ley Suprema sea siempre vigente.

En este sentido, los partidos políticos no pueden quedar al margen del control constitucional y no se pueden convertir en un instrumento de las oligarquías, ya que deben de tener presente que son el medio para que se haga efectiva la voluntad popular, de lo contrario, los supuestos representantes, sólo lo serán de intereses particulares y no del pueblo. Entonces, hasta que no se entienda lo anterior y exista una rotunda convicción por parte de los representantes de servir a su Estado y pueblo, seguirán existiendo hombres desiguales y hombres esclavos. Pero lo anterior, no debe generar sentimiento de desilusión, frustración e impotencia, porque siempre se debe luchar por las ideas de libertad e igualdad, mismas que nunca deben de ser arrebatadas por nadie, es así, que solo se puede vivir en Democracia Constitucional, la cual es el medio para lograr ser hombres y ciudadanos.

\section{BIBLIOGRAFÍA}

ABELLÁN, Á.M., Notas sobre la evolución del parlamento y de la representación política, Revista de Estudios Políticos, nº 92, 1996.

ARISTÓTELES, Política, 6 ${ }^{\mathrm{a}}$ ed., Centro de Estudios Políticos y Constitucionales, trad., Julián Marías y María Araujo, Madrid, 2005, libro, VI (IV), cap. 4,1, 291 b.

BEETHAM, D. y BOYLE, K., Introducing Democracy. 80 Questions and Answers, UNESCO, Francia, 1995.

BÖCKENFÖRDE, E.W., La democracia como principio constitucional, en Estudios sobre el Estado de Derecho y la Democracia, trad. Serrano de R. de Agapito, Madrid, Trotta.

BOVERO, M., Los desafíos de la democracia, Editorial UBIJUS, México, 2013.

BRYCE, J., Constituciones flexibles y constituciones rígidas, Centro de Estudios Constitucionales, Madrid, 1988.

CARPIZO, J. Desafíos Contemporáneos del Derecho Constitucional. En Nuevos Estudios Constitucionales Porrúa, México, 2000.

CARPIZO J., La Constitución Mexicana de 1917, 14ª ed., Porrúa, México, 2004. 
CARRÉ DE MALBERG, Teoría General del Estado (1922), trad. de Fernando de Lión Depetre José, Facultad de Derecho/UNAM-Fondo de Cultura Económica, México, 1998.

DAHL, R., La democracia y sus críticos (1989), trad. de Wolfson Leandro, Ediciones Paidos, Barcelona, 1992.

DUVERGER, M., Institutions politiques et droit constitucionnel, Press Universitaires de France, París, 1955.

GONZALES ROMERO, E., El sistema de partidos en México, Convergencia, México, 2006.

GREPPI, A., La democracia y su contrario, Editorial Trotta, Madrid, 2012.

HAMILTON, A., MADISON, J. y JAY, J., El Federalista, Fondo de Cultura Económica, $2^{\mathrm{a}}$ ed., México, 1957.

HELD, D., Models of Democracy, Stanford University Press, Standford, California, 1987.

JELLINEK G., Teoría General del Estado, trad. de los Rios Fernando, Editorial Comares, Granada, 2000

KELSEN, H., Teoría Pura del Derecho (1960), trad., de W. Roces, Porrúa, México, 1987.

KELSEN, H., Esencia y valor de la democracia (1977), trad. de R. Luengo Tapia y Legaz Lacambra L., Editorial Comares, Granada, 2002.

KELSEN, H., Teoría General del Estado (1925), trad. de Legaz Lacambra L., Editorial Comares, Granada, 2002.

KOBACH, K.W., The referéndum, Direct Democracy in Switzerland, Darthmouth, E.U.A., 1993.

KRIELE, M., Introducción a la Teoría del Estado fundamentos históricos de la legitimidad del Estado constitucional democrático, Depalma, Buenos Aires, 1980.

LOCKE, J., Segundo tratado sobre el gobierno civil, Alianza, Madrid, 1996.

LOEWENSTEIN, K., Teoría de la Constitución, 4ª reimpresión, Ariel, Barcelona, 1986.

MIRANDA CAMPOAMOR, F., Sistema electoral, Partidos Políticos y Parlamento, Colex, Madrid, 2003.

MONTESQUIEU, Del espíritu de las leyes, trad. Mercedes Blázquez y Pedro de Vega, Tecnos, $4^{\mathrm{a}}$ ed., Madrid, 1985. 
PRUD’HOMME, J.F., Consulta Popular y Democracia Directa, Instituto Federal Electoral, México, 1997.

ROUSSEAU, J.-J., El contrato social o principios de derecho político (1762), trad. de Villaverde María Jose, Tecnos, Madrid, 1988.

ROUSSEAU, J.-J., Proyecto de Constitución para Córcega. Consideraciones sobre Gobierno de Polonia y su proyecto de reforma (1765), trad. de Hermosa Andujar A., Tecnos, Madrid, 1988.

RUIPÉREZ, J., Libertad Civil e ideología democrática. De la Conciliación entre democracia y libertad a la confrontación liberalismo-democracia, Instituto de investigaciones Jurídicas, UNAM, México, 2008.

RUIPÉREZ, J., Adaptar la Constitución española a la realidad europea, en Encuentro: La Constitución de 1978: 40 años, en Club Financiero Atlántico, La Coruña, 20 de noviembre de 2018.

RUIPÉREZ, J., Vigencia y reforma de la Constitución española de 1978, en Encuentro: La Constitución de 1978: 40 años, en Club Financiero Atlántico, La Coruña, 19 de noviembre de 2018.

SARTORI, G., Teoría de la democracia, vol. 2, Alianza Editorial, México, 1988.

SCHMITT, C., Teoría de la Constitución, Alianza Editorial, Madrid, 1982.

SIEYÈS, E.-J., ¿Qué es el Tercer Estado? ensayo sobre los privilegios, Alianza, Madrid, 1989.

STUART MILL, J., Del gobierno representativo, Tecnos, Madrid, 1985.

VEGA, P. DE, Constitución y Democracia, en Rubio Núñez, Rafael (ed.), Obras Escogidas De Pedro De Vega, Centro de Estudios Políticos y Constitucionales, Madrid, 2017.

VEGA, P. DE, Estudios político-constitucionales, Instituto de Investigaciones Jurídicas, UNAM, México, 2016.

VEGA, P. DE, La democracia como proceso (Consideraciones en torno al republicanismo de Maquiavelo), Revista de Estudios Políticos, nº 120.

VEGA, P. DE, Legitimidad y representación en la crisis de la representación actual, Institut de Ciènces Politiques i Socials, Barcelona, 1998.

VEGA, P. DE, Legitimidad y representación en la crisis de la representación actual, Institut de Ciènces Politiques i Socials, Barcelona, 1998. 
VEGA, P. DE, Mundialización y Derecho Constitucional: La crisis del principio democrático en el constitucionalismo actual, en Revista de Estudios Políticos (Nueve Época), núm. 100, abril-junio, Centro de Estudios Políticos y Constitucionales, Madrid, 1998.

VEGA, P. DE, Significado constitucional de la representación política, en Rubio Núñez, Rafael (ed.), Obras Escogidas De Pedro De Vega, Centro de Estudios Políticos y Constitucionales, Madrid, 2017.

VEGA, P. DE, Supuestos históricos, bases sociales y principios políticos en el Derecho Constitucional democrático, en Rubio Núñez, Rafael (ed.), Obras Escogidas De Pedro De Vega, Centro de Estudios Políticos y Constitucionales, Madrid, 2017.

WONG MERÁZ, V.A., Constitución mexicana. Reforma y mutación, Porrúa, México, 2010.

\section{Páginas web}

PITKIN, H., The concept of representation, University of California Press, Berkeley, California, $1967, \quad$ p. $195, \quad$ disponible http://mavdisk.mnsu.edu/parsnk/Linked\%20Readings/Pol321/pitkin.pdf, consultado el 04 de julio de 2017. 